\title{
MENINGKATKAN KOMUNIKASI ASERTIF DALAM RELASI SOSIAL PADA REMAJA DI PANTI ASUHAN SOS CHILDREN'S VILLAGE SEMARANG
}

\author{
Bartolomeus Yofana Adiwena', Pius Heru Priyanto ${ }^{2}$ \\ ${ }^{1,2}$ Universitas Katolik Soegijapranata \\ 1adiwena@unika.ac.id; ${ }^{2}$ piusunika@gmail.com
}

\begin{abstract}
Adolescence is a period when someone begins to build broader social relationships and make decisions independently. However, many cases of adolescent social relationships actually provide negative experiences that hinder their development and threaten their future. Adolescents who live in orphanage have greater vulnerability to trapped in unhealthy social relationships. Assertiveness is the quality of a person to believe in himself, being able to communicate his thoughts, feelings, and emotions without driven by fear of others. Assertiveness assistance to adolescents in orphanages is important because assertiveness is a complement to the values and norms they receive in schools and orphanages. Without assertiveness, their knowledge of values and norms will not be effective. Assertiveness is a psychological construct that can be changed through a behavioral intervention program. With this assertiveness assistance program,we hope adolescents in orphanage could develop positive social relationships and reject negative invitations or pressures that make them trapped in unhealthy relationships, so that their future could be better.
\end{abstract}

Keywords: assertiveness assistance program, adolescence, orphanage, orphan

\section{PENDAHULUAN}

Masa remaja merupakan masa perkembangan transisi antara masa anak dan masa dewasa awal yang mencakup perubahan biologis, kognitif, sosial, dan emosional. Di masa ini, seseorang mulai memasuki periode persiapan untuk peran orang dewasa, dengan membangun hubungan sosial yang lebih luas dan mulai membuat keputusan secara mandiri (Santrock, 2010). Pada masa ini, hubungan sosial menjadi sumber penting dalam pencarian identitas remaja (Pittman, et al., 2011). Hubungan sosial yang dibentuk oleh remaja dapat berupa hubungan persahabatan, hubungan berpacaran, hubungan dalam kelompok kerja maupun hobi, dan sebagainya. Sayangnya, banyak remaja yang tidak siap, secara pengetahuan dan emosional, untuk mengantisipasi atau mengatasi pengalaman-pengalaman yang muncul dalam hubungan sosial yang dijalaninya.

Hubungan sosial pada remaja tidak selalu menghadirkan pengalaman yang positif bagi perkembangan fisik dan mental mereka. Faktanya, terdapat banyak kasus di mana hubungan sosial menghadirkan pengalaman negatif yang justru dapat menghambat perkembangan dan mengancam masa depan remaja. Kenakalan remaja, penyalahgunaan alkohol dan narkoba, kekerasan dalam berpacaran, dan hubungan seks pra nikah merupakan beberapa contoh permasalahan remaja yang sering ditimbulkan akibat hubungan sosial yang tidak sehat. BNN mencatat pada 2018 angka penyalahgunaan narkoba di kalangan pelajar di 13 ibu kota provinsi di Indonesia mencapai angkta 3,2 persen atau setara dengan 2,29 juta orang (Ristianto, 2018). Komnas Perempuan (2018) melaporkan bahwa di Indonesia sendiri terdapat 9.609 kasus kekerasan dalam ranah privat di tahun 2018 dan 1.873 kasus di antaranya terjadi dalam hubungan berpacaran. Selain itu, seperti diberitakan Lipitan6.com, riset Reckitt Benckiser Indonesia juga menunjukkan bahwa 33\% dari 500 orang yang disurvei di lima kota besar di Indoonesia mengaku pernah melakukan hubungan seks pra nikah, dan $58 \%$ di antaranya berada di usia 16 sampai 20 tahun (Prasasti, 2019). 
Terjebak dalam hubungan sosial yang tidak sehat tentu dapat memberi berbagai konsekuensi negatif, baik dalam jangka pendek maupun panjang. Penyalahgunaan alkohol dan narkoba dalam jangka panjang dapat merusak sistem saraf di otak dan mengganggu perkembangan fisik dan mental remaja seterusnya (Santrock, 2010). Remaja yang menjadi korban kekerasan dalam hubungan pacaran akan rentan mengalami depresi dan kecemasan, penurunan self esteem, terlibat dalam penyalahgunaan narkoba dan alkohol, serta menunjukkan perilaku antisosial seperti mencuri, mengintimidasi, atau perilaku kekerasan (Taquette \& Monteiro, 2019) Hubungan seks pra nikah meningkatkan risiko remaja terkena penyakit menular seksual seperti HIV/AIDS, kehamilan yang tidak diinginkan, aborsi yang tidak aman, putus sekolah, kematian ibu saat melahirkan, dan meningkatkan risiko terjadinya kekerasan dalam rumah tangga di masa depan (Shrestha, 2019).

Remaja yang tinggal di panti asuhan secara unik memiliki kerentanan (vulnerability) yang lebih besar dibandingkan remaja yang berada dalam keluarga inti, sehingga lebih berpotensi terjebak dalam hubungan sosial yang tidak sehat. Kerentanan yang dimiliki remaja di panti asuhan dapat berupa kerentanan secara ekonomi seperti jaminan keuangan untuk memenuhi kebutuhan hidup, secara psikologis seperti stigma sosial dan kurangnya kelekatan dengan pengasuh, serta kerentanan secara fisiologis atau kesehatan (Thompson, et al., 2012). Penelitian menunjukkan bahwa remaja dalam panti asuhan memiliki tingkat self esteem yang lebih rendah, serta menunjukkan perilaku agresif, depresi, dan kecemasan yang lebih tinggi dibandingkan remaja yang dibesarkan dalam lingkungan keluarga inti (Koumi, et al., 2012).

Meskipun dapat memberikan rasa aman dan kedekatan layaknya keluarga, panti asuhan tidak dapat memberikan pengasuhan dan kedekatan yang bersifat individual dan mendalam seperti pengasuhan dalam keluarga inti (Garvin, et al., 2012). Pengasuh di panti asuhan perlu merawat dan mengawasi banyak anak asuh, sehingga hubungan yang dimiliki menjadi tidak terlalu mendalam seperti pengasuhan dalam keluarga inti. Padahal, penelitian menunjukkan bahwa kedekatan, pengasuhan, dan dukungan dari orang tua menjadi faktor risiko utama remaja masuk ke dalam hubungan sosial yang tidak sehat (Buhi \& Goodson, 2007; Hillis, et al., 2010). Oleh karena itu, remaja di panti asuhan perlu memeroleh perlakuan atau pendampingan secara khusus agar mereka dapat menjaga dirinya, sehingga tidak terjebak dalam hubungan sosial yang tidak sehat.

SOS Children's Village Semarang merupakan salah satu lembaga non pemerintah yang mendedikasikan diri pada pengasuhan anak-anak yang ditinggalkan dan kehilangan orang tua. SOS Children's Village Semarang mengelola sebuah panti asuhan di Jalan Durian, Banyumanik, Semarang yang saat ini menjadi rumah bagi 104 orang yang kehilangan pengasuhan dari keluarganya; 37 orang di antaranya merupakan remaja sekolah menengah atas hingga perguruan tinggi.

Salah satu permasalahan yang terjadi pada remaja SMP dan SMA di SOS Children's Village Semarang adalah kurang dapatnya menunjukkan asertivitas dalam pergaulan sosial, sehingga mereka rentan terpengaruh pada bujuk rayu orang lain, baik dalam satu asrama maupun dari luar asrama. Wawancara terhadap pengasuh panti asuhan SOS Children's Village Semarang pada Februari 2020 mengungkap bahwa salah satu kekhawatiran utama pengasuh adalah terjerumusnya remaja panti asuhan ke dalam pergaulan atau hubungan sosial yang tidak sehat. Dari pengamatan para pengasuh, remaja panti asuhan memiliki kepribadian yang rentan, seperti kepercayaan diri yang rendah, tidak mudah bergaul, dan tidak mudah terbuka terhadap pengasuhnya. Hal ini membuat mereka semakin berisiko terjerumus dalam pergaulan atau hubungan sosial yang tidak sehat. Pengasuh panti asuhan mengharapkan agar remaja panti asuhan dapat memeroleh 
pendampingan dan pengarahan dari pihak-pihak yang kompeten agar mereka dapat menjaga diri dan mengembangkan hubungan sosial yang positif demi masa depan mereka. Untuk itu perlu dilakukan pendampingan tentang aseritivtas dalam relasi sosial agar mereka tidak mudah terpengaruh pada ajakan atau bujur rayu orang lain.

Asertivitas yang rendah ditengarai menjadi salah satu penyebab utama remaja terjebak dalam pergaulan atau hubungan yang tidak sehat. Asertivitas adalah kualitas seseorang untuk percaya pada dirinya sendiri, mampu mengomunikasikan pikiran, perasaan, dan emosinya tanpa dipengaruhi atau takut kepada orang lain (Maimunah, 2017). Asertivitas berbeda dengan perilaku agresif; Menjadi asertif tidak berarti menggunakan kekerasan atau meluapkan kemarahan. Orang yang asertif akan berusaha membela diri untuk melindungi hak-hak mereka dengan menyatakan secara tegas apa yang diinginkan dan tidak diinginkan. Penelitian menunjukkan bahwa asertivitas sesorang dapat mengurangi kerentanan mereka terhadap kekerasan dalam hubungan romantis (Diadiningrum \& Endrijati, 2014; Livingston, et al., 2007). Selain itu, program peningkatan asertivitas yang dilakukan oleh Maimunah (2017) juga terbukti dapat mengurangi perilaku seks pra nikah pada remaja wanita. Dengan bersikap asertif, remaja dapat dengan tegas menolak ajakan atau pengaruh-pengaruh negatif dalam hubungan sosial yang dijalaninya, serta keluar dari hubungan tersebut bila dirasa hubungan itu bersifat destruktif.

Penulis berpendapat bahwa pendampingan asertivitas menjadi penting untuk diberikan karena merupakan penunjang atas nilai-nilai dan norma yang mereka peroleh di sekolah maupun panti asuhan. Pendidikan tentang nilai dan norma memberikan pengetahuan kepada remaja tentang apa yang baik dan boleh, serta apa yang tidak baik dan tidak boleh dilakukan, sedangkan pendampingan asertivitas akan membuat remaja berani dan berkomitmen untuk mengambil keputusan yang tepat sesuai pengetahuan dan nilai yang mereka peroleh tanpa takut terhadap pendapat lingkungan sosial. Tanpa asertivitas, pengetahuan tentang nilai dan norma yang dimiliki remaja tidak akan menjadi efektif. Selain itu, asertivitas juga merupakan konstruk psikologis yang relatif dapat diubah melalui program intervensi perilaku (Livingston, et al., 2007) Dengan pendampingan asertivitas ini, diharapkan remaja di panti asuhan dapat mengembangkan hubungan sosial yang positif dan berani menolak ajakan atau tekanan yang membuat mereka terjebak dalam hubungan yang tidak sehat dan merugikan diri mereka sendiri, sehingga pada akhirnya mendukung mereka memiliki masa depan yang cerah.

Berdasarkan pengamatan dan data-data yang diperoleh penulis, remaja di panti asuhan SOS Children's Village Semarang memiliki kepribadian yang rentan, sehingga menyebabkan mereka berisiko terjerumus ke dalam pergaulan atau hubungan sosial yang tidak sehat. Asertivitas yang rendah menjadi salah satu penyebab utama remaja terjebak dalam pergaulan atau hubungan yang tidak sehat. Oleh karena itu, program yang penulis lakukan ini bertujuan untuk meningkatkan pengetahuan (knowledge) tentang komunikasi yang asertif pada remaja di panti asuhan SOS Children's Village Semarang. Dengan komunikasi asertif, remaja diharapkan mampu menghindari dan membentengi mereka dari pergaulan atau hubungan sosial yang tidak sehat.

\section{METODE}

Kegiatan ini merupakan kegiatan pendampingan terhadap remaja panti asuhan SOS Children's Village Semarang. Pendampingan yang dimaksudkan adalah kegiatan pemberian informasi, sharing, pembentukan komitmen, dan motivasi yang didampingi fasilitator agar remaja SOS Children's Village Semarang dapat berkomunikasi secara asertif dan menghindari pergaulan yang tidak sehat. Pendekatan yang digunakan adalah contextual learning, yaitu pendekatan belajar atau pendampingan dengan cara 
mengaitkan materi yang diberikan dengan situasi dunia nyata atau pergaulan yang dialami remaja sehari-hari (Davtyan, 2014). Masalah yang sering dihadapi oleh remaja SOS Children's Village adalah kurang asertif dalam berkomunikasi dan berhubungan sosial. Melalui pendekatan contextual learning, diharapkan remaja dapat belajar dari hal-hal yang mereka alami untuk kemudian menjadi lebih asertif ke depannya.

Dalam melakukan kegiatan atau pendampingan ini, prosedur kerja yang dilakukan adalah sebagai berikut.

1. Observasi dan wawancara terhadap pengurus SOS Children's Village Semarang tentang permasalahan riil yang dihadapi remaja di sana sehari-harinya.

2. Studi dokumentasi tentang jumlah remaja SMP, SMA, Perguruan Tinggi, pengurus, dan pengasuh yang ada di SOS Children's Village Semarang.

3. Pemberian pendampingan kepada remaja SOS children's Village Semarang terpaksa dilakukan dengan metode jarak jauh/daring karena adanya pandemi Covid-19 dan hanya dilakukan satu kali pertemuan dari rencana awal tiga kali pertemuan; pihak pengurus SOS Children's Village Semarang hanya memberikan kesempatan pendampingan secara daring (menggunakan Google Meet) sebanyak satu kali untuk menjaga kesehatan penghuni SOS Children's Village Semarang.

4. Pemberian pendampingan kepada remaja SOS Children's Village Semarang dilakukan pada Rabu, 17 Juni 2020 pukul 10.00 sampai 12.00 WIB. Pemberian pendampingan hanya dilakukan satu kali karena SOS Children's Village memiliki agenda yang padat bersama pendamping atau organisasi sosial lainnya.

5. Mentor yang menampingi berjumlah dua orang, yaitu Pius Heru Priyanto dan Bartolomeus Y. Adiwena.

6. Pihak remaja yang menjadi peserta pengabdian masyarakat dikumpulkan dalam sebuah aula dan didampingi para pengurus. Mereka menyaksikan pendampingan melalui Google Meet yang ditampilkan di layar proyekor.

7. Acara pendampingan dalam satu pertemuan dibagi menjadi tiga sesi, yaitu:

a. Sesi 1: Asertivitas dan pergaulan yang sehat secara umum oleh Pius Heru Priyanto

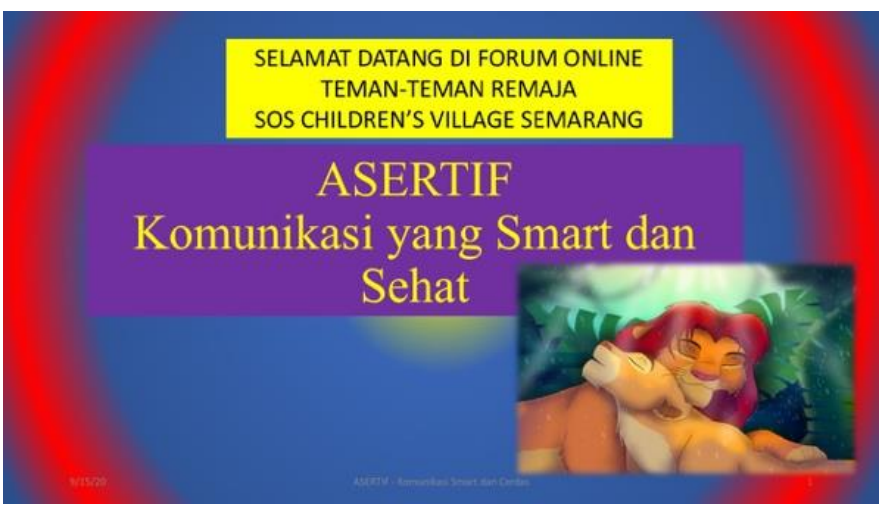

Gambar 1. Gambaran materi sesi 2 
b. Sesi 2: Langkah-langkah praktis tentang asertivitas oleh Bartolomeus Y. Adiwena

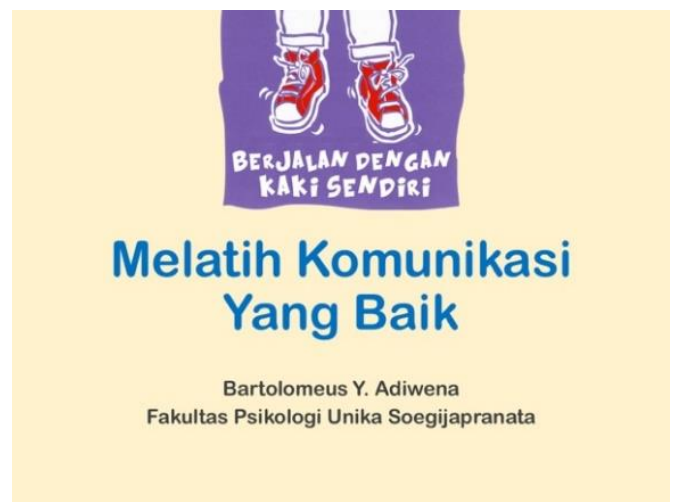

Gambar 2. Gambaran materi sesi 2

c. Sesi 3: Tanya jawab.

\section{HASIL KARYA UTAMA DAN PEMBAHASAN}

Anak-anak yang tinggal di panti asuhan dan memiliki kerentanan membutuhkan dukungan dan pelatihan sosial untuk membantu mereka memiliki kepercayaan diri yang baik (Mynard, et al., 2000; Schroeder, et al., 2012). Ancaman perundungan oleh teman sebaya maupun pergaulan atau hubungan sosial yang tidak sehat meningkat setiap hari dan semakin penting untuk diperhatikan. Salah satu solusinya adalah melatih anak-anak agar mampu menunjukkan perilaku yang sesuai, seperti asertivitas (Boket, 2016). Pelatihan asertivitas penting untuk diberikan sejak masa remaja ketika tanggung jawab pribadi dan sosial mereka meningkat (Avşar \& Ayaz Alkaya, 2017). Dalam penelitian ini, meskipun tidak terukur secara kuantitatif, tapi tingkat pemahaman anak-anak tentang perilaku asertif meningkat.

Secara umum, mitra pengabdian masyarakat, baik pengurus maupun remaja SOS Children's Village Semarang, menunjukkan keterlibatan yang sangat baik. Pengurus terlibat aktif dalam pelaksanaan kegiatan pendampingan dengan mengkoordinasikan semua remaja penghuni SOS Children's Village pada waktu yang ditetukan di sebuah aula. Selain itu, pengurus terlibat aktif dalam pelaksanaan kegiatan pendampingan dengan menyediakan sarana dan prasarana untuk menunjang jalannya kegiatan, seperti aula, meja dan kursi, internet, dan proyektor. Remaja yang menjadi peserta pendampingan terlibat dan serius memperhatikan materi yang diberikan oleh mentor. Selain itu, terdapat beberapa remaja yang memberikan pertanyaan saat diberikan kesempatan.

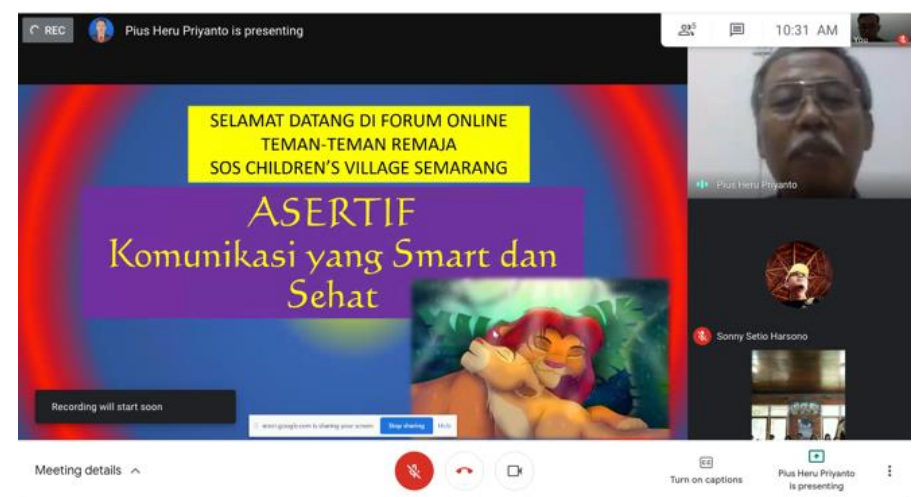

Gambar 3. Proses pemberian materi sesi 1 


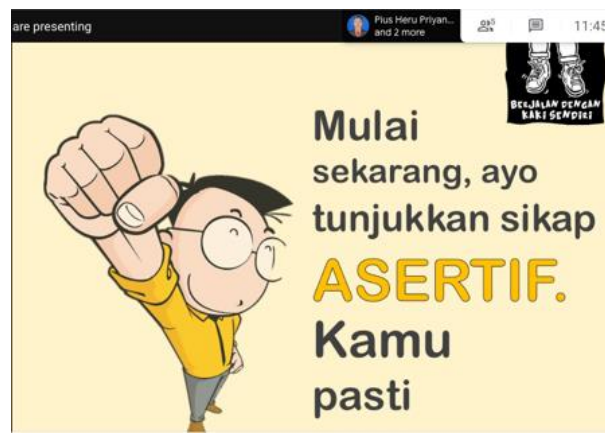

Gambar 4. Proses pemberian materi sesi 2

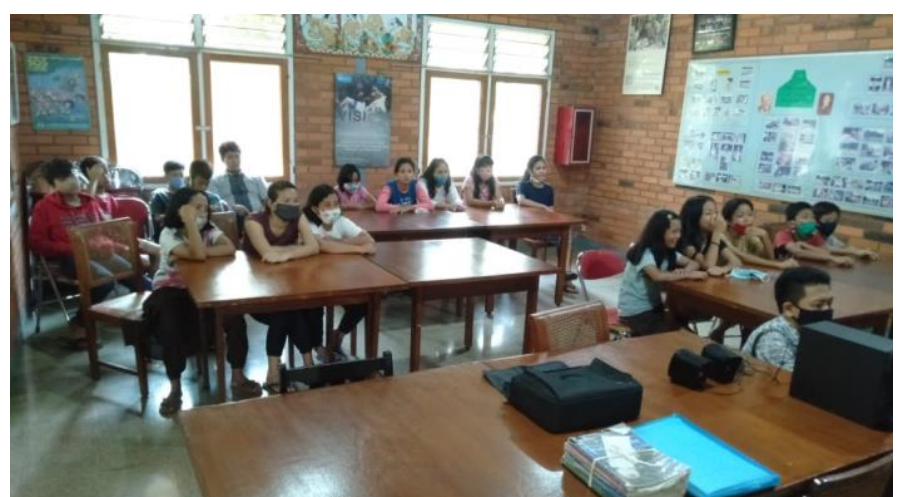

Gambar 5. Situasi remaja yang mengikuti pendampingan daring dari aula SOS Children's Village.

Program ini dapat berjalan dengan lancar dan cukup baik, walaupun terdapat sedikit perubahan desain kegiatan karena adanya pandemi Covid 19. Kegiatan yang awalnya didesain dalam tiga pertemuan tatap muka akhirnya hanya dapat dilakukan dalam satu kali pertemuan secara daring. Pengurus SOS Children's Village menyambut program pengabdian masyarakat ini dengan hangat karena program pendampingan ini sangat bermanfaat bagi remaja asuhan di sana. Remaja SOS Children's Village yang menjadi sasaran pendampingan juga menunjukkan antusiasme dan semangat mereka saat mengikuti kegiatan pendampingan ini.

Setelah pendampingan ini, remaja menjadi lebih memahami prinsip-prinsip interaksi sosial yang baik dan benar, manfaat komunikasi asertif, dan langkah praktis berkomunikasi secara asertif, yaitu merasa diri berharga, selalu berkata dengan jujur, mengungkapkan keinginan secara terbuka, menggunakan pernyataan positif, jangan membicarakan kejelakan orang lain, serta menatap mata lawan bicara dan menggunakan intonasi yang ramah. Dalam proses pendampingan beberapa peserta yang belum begitu paham juga tidak segan untuk bertanya dan melakukan sharing kasus yang mereka alami, sehingga proses diskusi dapat lebih diterima oleh peserta. Peningkatan pemahaman tentang asertivitas dapat diketahui dari antusiasme dan keseriusan remaja SOS Children's Village Semarang yang mengikuti kegiatan. Mereka banyak bertanya dan ada beberapa remaja yang membagikan pengalamannya dan langsung meminta saran solusi.

Pelatihan asertivitas pada remaja di SOS Children's Village Semarang tentunya memiliki berbagai manfaat bagi remaja tersebut, seperti: Membantu mereka mengungkapkan kemarahan dan ketidaksukaan terhadap sesuatu, membantu mereka yang menunjukkan kesopanan berlebih dan selalu mengorbankan diri sendiri, dan membantu mereka yang merasa kesulitan mengatakan "tidak" (Bulantika \& Sari, 2019). Oleh karena itu, dapat ditarik kesimpulan bahwa pelatihan asertif membantu meningkatkan 
kemampuan mengkomunikasikan apa yang diinginkan, dirasakan, dan dipikirkan remaja dengan tetap menjaga dan menghormati hak dan perasaan orang lain. Pelatihan asertif dirancang untuk mengembangkan keterampilan individu yang terganggu oleh kecemasan dengan menggunakan berbagai teknik yang tersedia, sehingga individu dapat memiliki perilaku asertif yang diinginkan (Bulantika \& Sari, 2019).

Kemampuan asertivitas yang baik tidak hanya membentengi remaja dari pengaruh pergaulan yang tidak sehat. Penelitian menunjukkan bahwa dengan meningkatnya asertivitas seseorang, perilaku agresinya pun akan berkurang (Khalatbari, et al., 2010). Peneliti meyakini bahwa seseorang yang memiliki asertivitas baik akan bertindak secara adil, berkomitmen untuk saling menghormati dalam komunikasi sosial, serta memiliki keterampilan penyelesaian konflik yang adaptif, sehingga tidak menunjukkan perilaku agresif (Ashouri, et al., 2009). Melalui program ini, diharapkan remaja di SOS Children's Village Semarang tidak hanya mampu membentengi diri mereka dari pengaruh-pengaruh lingkungan yang kurang baik, tapi juga mampu menunjukkan sikap yang baik dan jauh dari kekerasan.

Kegiatan pengabdian ini memiliki beberapa keterbatasan atau kekurangan sebagai akibat adanya pandemi Covid19. Pertama, kami tidak dapat menjalankan pendampingan secara utuh dan intensif sesuai rencana awal karena kami hanya bisa bertemu sebanyak satu kali secara daring. Kedua, kami tidak dapat melakukan tindak lanjut (follow up) tentang keberhasilan riil pendampingan yang kami lakukan. Pengukuran secara kuantitatif menggunakan pre dan post test juga tidak memungkinkan karena remaja di SOS Children's Village Semarang tidak dapat mengisi Google Form secara individual akibat terbatasnya perangkat yang dimiliki. Sedangkan, pengukuran secara kualitatif juga tidak dimungkinkan karena kami tidak dapat melakukan observasi dan pertemuan/sharing dengan peserta tentang pengalaman mereka setelah mendapat pendampingan asertivitas. Namun, melihat antusiasme dan pemahaman peserta pada satu kali pendampingan yang dilakukan, kami optimis bahwa remaja di SOS Children's Village Semarang akan dapat berkomunikasi dengan lebih asertif, dan pada akhirnya dapat menghindari pergaulan yang tidak sehat.

\section{KESIMPULAN}

Secara umum, program ini dapat berjalan dengan lancar dan cukup baik, walaupun terdapat sedikit perubahan desain kegiatan karena adanya pandemi Covid 19. Melalui program pendampingan ini, remaja di panti asuhan SOS Children Vilage memperoleh peningkatan pengetahuan (knowledge) tentang prinsip-prinsip interaksi sosial yang baik dan benar, manfaat komunikasi asertif, dan langkah praktis berkomunikasi secara asertif. Setelah mengikuti kegiatan pendampingan ini, diharapkan remaja mampu menunjukkan perilaku asertif, sehingga mampu menghindari dan membentengi diri mereka dari pergaulan atau hubungan sosial yang tidak sehat.

Pada program pendampingan asertivitas pada remaja ini, kami menitikberatkan pada peningkatan pemahaman (knowledge) remaja. Di tahap selanjutnya, pendampingan asertivitas masih perlu dilakukan dalam bentuk praktek (roleplay), sehingga remaja dapat benar-benar melakukan komunikasi asertif dalam pergaulan mereka. Selain itu, perlu diberikan sebuah sesi follow up untuk melihat perkembangan dan kesulitan yang mereka rasakan di pergaulan riil mereka untuk selanjutnya diberikan bantuan atau solusi. Dengan begitu, diharapkan remaja menjadi benar-benar dapat menerapkan pola komunikasi yang asertif. 


\section{UCAPAN TERIMA KASIH}

Penulis mengucapkan terima kasih kepada LPPM Universitas Katolik Soegijapranata yang telah memberikan dukungan pendanaan sehingga kegiatan pengabdian masyarakat ini dapat terlaksana. Penulis juga berterima kasih kepada pengurus Panti Asuhan SOS Children's Village Semarang yang terlah memberikan dukungan sistem informasi sehingga kegiatan pengabdian masyarakat ini dapat terlaksana secara daring dengan lancar.

\section{DAFTAR PUSTAKA}

Arrindell, W. A., Sanavio, E. \& Sica, C., 2002. Introducing a short form version of the Scale for Interpersonal Behaviour (s-SIB) for use in Italy. Psicoterapia Cognitiva e Comportamentale, Volume 8, p. 3-18.

Ashouri, A., Torkman, M. M. \& Fadaee, Z., 2009. The Effectiveness of Assertive Training Group Therapy in Decreasing Aggression and Improving Academic Achievement in High School Students. Iranian Journal of Psychiatry and Clinical Psychology, Volume 14, pp. 389-393.

Avşar, F. \& Ayaz Alkaya, S., 2017. The effectiveness of assertiveness training for schoolaged children on bullying and assertiveness level. Journal of Pediatric Nursing, Volume 36, p. 186-190.

Boket, E. G. B. M. K. L. \&. H. S. A., 2016. The effect of assertiveness skills training on reduction of verbal victimization of high school students. International journal of humanities and cultural studies, pp. 690-699.

Buhi, E. R. \& Goodson, P., 2007. Predictors of Adolescent Sexual Behavior and Intention: A Theory-Guided Systematic Review. Journal of Adolescent Health, Volume 40, pp. 4-21.

Bulantika, S. Z. \& Sari, P., 2019. The Effectiveness of Assertive Training Techniques and ThoughtStopping Techniques to Increase Student Assertiveness Ability. Biblio Couns: Jurnal Kajian Konseling dan Pendidikan, 2(3), pp. 109-116.

Davtyan, R., 2014. Contextual Learning. Bridgpeort, University of Bridgeport.

Diadiningrum, J. R. \& Endrijati, H., 2014. Hubungan antara Sikap Asertivitas dengan Kecenderungan Menjadi Korban Kekerasan dalam Pacaran pada Remaja. Jurnal Psikologi Pendidikan dan Perkembangan, 3(2), pp. 97-102.

Garvin, M. C., Tarullo, A. R., Van Ryzin, M. \& Gunnar, M. R., 2012. Postadoption parenting and socioemotional development in postinstitutionalized children.. Development and Psychopathology, 24(1), pp. 35-48.

Hillis, S. D. et al., 2010. The Protective Effect of Family Strengths in Childhood against Adolescent Pregnancy and Its Long-Term Psychosocial Consequences. The Permanente Journal, 4(3), pp. 18-27.

Khalatbari, J., Ghorban, S. S. \& Mobaleghi, N., 2010. Comparing the effectiveness of the self-assertiveness training and problem-solving on the aggression and adaptation in students. Quarterly Journal of Educational Psychology, Volume 1, pp. 93-110.

Komnas Perempuan, 2018. Tergerusnya Ruang Perempuan dalam Pusaran Politik Populisme, Jakarta: Komnas Perempuan.

Koumi, M. A. E. et al., 2012. Psychiatric Morbidity among a Sample of Orphanage Children in Cairo. Hindawi Publishing Corporation International Journal of Pediatrics. 
Livingston, J. A., Testa, M. \& VanZile-Tamsen, C., 2007. The Reciprocal Relationship Between Sexual Victimization and Sexual Assertiveness. Violence Against Women, 13(3), p. 298-313.

Maimunah, S., 2017. Enhancement of Assertiveness in Female Adolescents with SEA (Self Efficacy to Assertiveness) Card to Prevent Pre-Marital Sexual Behavior. International Journal of Science and Research, 6(8), pp. 94-96.

Mynard, H., Joseph, S. \& Alexander, J., 2000. Peer-victimisation and posttraumatic stress in adolescents. Personality and Individual Differences, Volume 29, p. 815-821.

Pittman, J., Keiley, M., Kerpelman, J. \& Vaughn, B., 2011. Attachment, identity, and intimacy: Parallels between Bowlby's and Erikson's paradigms. Journal of Family Theory and Review, Volume 3, p. 32-46.

Prasasti, G. D., 2019. HomeHealthSeks Riset: 33 Persen Remaja Indonesia Lakukan Hubungan Seks Penetrasi Sebelum Nikah. [Online] Available at: https://www.liputan6.com/health/read/4016841/riset-33-persenremaja-indonesia-lakukan-hubungan-seks-penetrasi-sebelum-nikah\# [Accessed 2020].

Ristianto, C., 2018. BNN Sebut Penyalahgunaan dan Peredaran Narkotika Semakin Meningkat.

[Online]

Available at: https://nasional.kompas.com/read/2019/06/26/11421691/bnn-sebutpenyalahgunaan-dan-peredaran-narkotika-semakin-meningkat

Santrock, J. W., 2010. Adolescence. 16th ed. New York: McGraw-Hill.

Schroeder, B. A. et al., 2012. The implementation of a statewide bullying prevention program: Preliminary findings from the field and the importance of coalitions. Health Promotion Practice, Volume 13, pp. 489-495.

Shrestha, R. B., 2019. Premarital Sexual Behaviour and its Impact on Health among Adolescents. Journal of Health Promotion, Volume 7, pp. 43-52.

Taquette, S. R. \& Monteiro, D. L. M., 2019. Causes and consequences of adolescent dating violence: a systematic review. Journal of Injury and Violence, 11(2), pp. 137147.

Thompson, R. T. et al., 2012. The Vulnerabilities of Orphaned Children Participating in Research: A Critical Review and Factors for Consideration for Participation in Biomedical and Behavioral Research. Journal of empirical research on human research ethics, 7(4), pp. 55-66. 